REVIEW ARTICLE OPEN

\title{
A new era in cytomegalovirus vaccinology: considerations for rational design of next-generation vaccines to prevent congenital cytomegalovirus infection
}

\author{
Cody S. Nelson ${ }^{1}$, Betsy C. Herold ${ }^{2}$ and Sallie R. Permar ${ }^{1}$
}

\begin{abstract}
Human cytomegalovirus (HCMV), a member of the beta-herpesvirus family, is the most common cause of congenital infection worldwide as well as an important cause of morbidity in transplant recipients and immunosuppressed individuals. An estimated 1 in 150 infants are infected with HCMV at birth, which can result in lifelong, debilitating neurologic sequelae including microcephaly, sensorineural hearing loss, and cognitive impairment. Natural maternal immunity to HCMV decreases the frequency of reinfection and reduces risk of congenital transmission but does not completely protect against neonatal disease. Thus, a vaccine to reduce the incidence and severity of infant infection is a public health priority. A variety of candidate HCMV vaccine approaches have been tried previously, including live-attenuated viruses, glycoprotein subunit formulations, viral vectors, and single/bivalent DNA plasmids, but all have failed to reach target endpoints in clinical trials. Nevertheless, there is a great deal to be learned from the successes and failures of the HCMV vaccine field (both congenital and transplant-associated), as well as from vaccine development efforts for other herpesvirus pathogens including herpes simplex virus 1 and 2, varicella zoster virus, and Epstein-Barr virus. Here, we review those successes and failures, evaluating recent cutting-edge discoveries that have shaped the HCMV vaccine field and identifying topics of critical importance for future investigation. These considerations will inform rational design and evaluation of next-generation vaccines to prevent HCMV-associated congenital infection and disease.
\end{abstract}

npj Vaccines (2018)3:38; doi:10.1038/s41541-018-0074-4

\section{CLINICAL ENDPOINT OF CONGENITAL HCMV VACCINATION TRIALS}

Over the past 50 years of vaccine development to prevent congenital CMV (cCMV) infection, the field has struggled with how best to clinically evaluate vaccine efficacy. Given that CCMV is somewhat rare at a population-level (1 in 150 pregnancies) and occurs in an extraordinarily vulnerable patient population, what is the most appropriate and practical clinical trial endpoint? Should vaccination seek to reduce viral spread from toddlers, prevent infection of the mother, block viral transmission across the placenta, and/or reduce pathogenesis in the infant? ${ }^{1}$ The endpoint utilized in phase 2 efficacy trials of the glycoprotein B (gB) subunit vaccine was a reduction in the rate of maternal HCMV acquisition. ${ }^{2,3}$ As preexisting natural HCMV immunity is not protective against HCMV reinfection or against viral reactivation, there is a certain degree of pessimism among researchers who contend that vaccine-elicited sterilizing maternal immunity is an unrealistic goal. ${ }^{4}$ Yet, it is quite encouraging to future vaccine development efforts that the gB subunit vaccine demonstrated $\sim$ $50 \%$ efficacy in preventing HCMV acquisition in women, ${ }^{2,3}$ and reduced viremia in organ transplant recipients. ${ }^{5}$ Potentially, if the primary outcome of $\mathrm{gB}$ subunit vaccination studies had been the prevention of fetal infection, the measured vaccine efficacy might have been higher.

Given that sterilizing immunity against HCMV infection may be difficult to achieve, one alternative approach (or proposal) is to prioritize a reduction in the incidence of fetal infection and/or severity of congenital disease as a clinical endpoint. ${ }^{1}$ Importantly, both guinea pig and rhesus macaque challenge models of cCMV transmission have given confidence to the assertion that vaccines can modulate the incidence and severity of congenital infection. In guinea pigs, immunization with a gB subunit vaccine, ${ }^{6}$ liveattenuated vaccine, ${ }^{7,8}$ or LCMV vector ${ }^{9}$ as well as passive infusion of a $\mathrm{gH}$-specific $\mathrm{mAb}^{10}$ have been shown to reduce rates of $\mathrm{cCMV}$ infection. Furthermore, we have demonstrated that preexisting HCMV-specific antibody can reduce CCMV transmission in a rhesus monkey model. ${ }^{11}$ These findings justify further preclinical and clinical evaluation of vaccine candidates for their ultimate purpose -to prevent congenital infant infection and disease.

\section{SUCCESSES IN HERPESVIRUS VACCINE DEVELOPMENT}

Over the past several decades, there have been major advances in herpesvirus vaccine development. Because of the challenge of inducing sterilizing immunity against herpesviruses, vaccine efficacy is frequently assessed for both preventative efficacy (prevention of acquisition) and therapeutic efficacy (improvement of disease). The crowning achievement of herpesvirus vaccine research is the development of safe and efficacious varicella zoster virus (VZV) vaccines to both prevent "chickenpox" and provide a therapeutic reduction in symptomatic shingles and/or postherpetic neuralgia (PHN). A live-attenuated virus vaccine, which demonstrated vaccine efficacy for the prevention of chickenpox disease ranging from 70 to $96 \%$ depending on preparation, ${ }^{12}$ was

\footnotetext{
${ }^{1}$ Human Vaccine Institute, Duke University Medical Center, Durham, NC, USA and ${ }^{2}$ Department of Pediatrics, Albert Einstein College of Medicine, Bronx, NY, USA Correspondence: Sallie R. Permar (sallie.permar@dm.duke.edu)
}

Received: 12 April 2018 Revised: 7 July 2018 Accepted: 11 July 2018 Published online: 20 September 2018 
initially approved in 1995. Subsequently, the same vaccine, which was $\sim 60 \%$ effective against zoster/PHN, gained FDA approval for these additional indications. ${ }^{13}$ More recently, a VZV gE subunit vaccine (combined with the adjuvant AS01B) demonstrated a remarkable $97 \%$ efficacy at preventing zoster in clinical trial and was approved for that indication. ${ }^{14}$ It is remarkable that the subunit vaccine outperformed the live-attenuated vaccine, although the dosing regimen was different (two doses of subunit versus single dose of live-attenuated vaccine strain) and immunological responses that contribute to protection may be distinct. This $\mathrm{gE}$ subunit vaccine boosts both humoral and polyfunctional CD4 + T-cell responses to $\mathrm{gE}$, which is the most abundant viral glycoprotein expressed by VZV-infected cells. ${ }^{15}$ Finally, though less well-known, there have also been successful vaccination-based eradication campaigns for veterinary herpesviruses including bovine herpesvirus $1 .{ }^{16}$ The HCMV vaccine field stands to learn a great deal from these successes-most importantly that such a vaccine is possible.

The HCMV gB subunit vaccine is the most efficacious tested to date, achieving $\sim 50 \%$ efficacy in preventing primary HCMV infection in multiple clinical trials. ${ }^{2,3}$ Intriguingly, the use of a subunit vaccine platform has met with mixed success for several other herpesvirus pathogens. A subunit vaccine comprised of glycoprotein D from HSV-2 (gD-2) combined with the adjuvant AS04, initially demonstrated 74\% efficacy in HSV-1/2-seronegative women with long-term HSV-2-infected partners, but was not effective in HSV-1 seropositive women or in men. ${ }^{17}$ However, in the larger phase 3 "Herpevac" trial field study, which enrolled > 8000 HSV-1/2-seronegative women, the same vaccine was $20 \%$ efficacious (95\% confidence interval: -29 to 50\%) against all genital herpes disease, although 58\% (12-80\%) efficacy was observed against genital HSV-1 disease. Efficacy against HSV-1 infection (e.g., seroconversion with or without signs of disease) was $35 \%(13-52 \%))$ and there was no efficacy against HSV-2 infection ( $-8 \%$; $(-59$ to $26 \%)$ ). A subsequent analysis found that gD-2 binding antibodies, but not CD4 + T-cell responses, correlated with HSV-1 (but not HSV-2) protection. ${ }^{18}$ A subunit vaccine platform has also been attempted for Epstein-Barr virus (EBV). In a phase 2 study, the gp350 vaccine for EBV demonstrated $78 \%$ efficacy in preventing infectious mononucleosis, though negligible protection against asymptomatic EBV acquisition. ${ }^{19}$ These partial successes clearly indicate that a subunit vaccine platform to prevent herpesvirus pathology is indeed possible. However, clinical trial data indicate that such herpesvirus subunit vaccines may need to be focused on a subset of herpesvirus-related disease processes (zoster, HSV-1 genital disease, mononucleosis, etc), and may not be effective at preventing infection or eliciting "sterilizing" immunity.

\section{THE CHALLENGE OF SUPERINFECTION}

Given that the HCMV basic reproductive rate $\left(R_{0}\right)$ is 1.7 (e.g., each person infects 1.7 others on average), ${ }^{20}$ effective immunity in a mere $41 \%$ of the population would restrict population-level transmission if this virus behaved like any other pathogen. One of the largest challenges of HCMV vaccine development remains the ability of this "changeling demon" ${ }^{21}$ to superinfect previously exposed individuals, which recent epidemiologic data has suggested can result in a comparable level of infant congenital disease in seropositive and seronegative populations. ${ }^{22}$ Thus, in addition to a focus on vaccine-elicited protective immunity among HCMV-naïve individuals, future studies should investigate whether vaccination can boost natural immunity and enhance protection against superinfection/reactivation and HCMV-related disease. ${ }^{23}$ Preliminary vaccination studies investigating the use of the $\mathrm{gB}$ / MF59 subunit vaccine in seropositive individuals indicate that vaccination can indeed improve upon natural immunity, specifically gB-specific CD4 + T-cell responses. ${ }^{24}$ Furthermore, in a cohort of HCMV-seropositive transplant recipients, gB vaccination boosted neutralizing antibody responses targeting the $A D-2$ neutralizing epitope, and enhanced AD-2 binding was associated with a reduced incidence of HCMV viremia. ${ }^{25}$

\section{HUMORAL VS. CELLULAR PROTECTIVE IMMUNITY}

It is anticipated that any efficacious HCMV vaccine may have to engage multiple branches of the immune system. ${ }^{23}$ Neutralizing antibodies have been frequently associated with protection against CCMV transmission. ${ }^{26-29}$ Furthermore, an apparent reduction in the rate and severity of cCMV infection was observed following passive infusion of HCMV-neutralizing antibodies to infected women, ${ }^{30,31}$ though this protection was not replicated in a recent phase 3 , placebo-controlled trial. ${ }^{32}$ In addition to neutralizing antibodies, high-magnitude HCMV-specific CD4 + Tcell responses have been repeatedly correlated with protection against CCMV infection, ${ }^{33,34}$ suggesting that this cell type is likely critical in maturation of the protective antigen-specific immune response.

The debate over antibodies vs. cellular immune responses as correlates of protection is shared by the HSV vaccine field. HSV gD-binding antibodies, which exhibit neutralizing activity in vitro, were associated with modest protection against HSV-1 disease in the Herpevac trial, although the primary endpoint (protection against genital herpes) was not achieved. ${ }^{18}$ Similar to the HCMV $\mathrm{gB}$ vaccine trials, ${ }^{2,3}$ it is unclear whether the limited vaccine efficacy was due to: (1) inadequate neutralizing and/or epitopespecific gD antibody responses, ${ }^{35}$ (2) need for a combination of viral antigens, (3) requirement for non-neutralizing antibody functions such as antibody-dependent cellular cytotoxicity (ADCC), and/or (4) failure to elicit potent antigen-specific T-cell immunity. The highly efficacious live-attenuated VZV vaccine elicits both robust and durable humoral immunity ${ }^{36}$ as well as potent CD4 + / CD8 + T-cell responses. ${ }^{37}$ Furthermore, the VZV gE subunit vaccine stimulates high-magnitude gE-specific antibodies and CD4 + , but not CD8 + , T-cell responses. ${ }^{38}$ These data suggest that humoral and cellular immunity may both be necessary for optimal herpesvirus vaccine efficacy.

Our group previously established a nonhuman primate model for CCMV transmission ${ }^{39}$ observing that depletion of CD4 + T cells prior to primary rhesus CMV (RhCMV) infection resulted in universal congenital RhCMV infection and a high frequency of fetal loss. We subsequently used this model to investigate the ability of preexisting neutralizing antibodies to protect against placental CMV transmission and fetal loss following primary maternal infection. Pregnant, RhCMV-seronegative, CD4 + T-cell depleted dams were treated with hyperimmune globulin purified from RhCMV-seropositive monkeys, then inoculated with RhCMV. Intriguingly, the pre-infused antibody provided complete protection against fetal loss, while the most potently neutralizing HIG product blocked placental RhCMV transmission. ${ }^{11}$ These studies indicate that antibody alone can be protective against CCMV transmission and could be a primary target of vaccines to eliminate this disease. We hypothesize that depletion of CD4+ T cells impacts the incidence of congenital RhCMV infection due to the impact on antibody maturation pathways, though we have not excluded any potential protection of cell-mediated immunity in the rhesus monkey model.

\section{IMMUNOGEN SELECTION}

HCMV encodes 165 unique proteins, ${ }^{40}$ yet previous HCMV vaccination efforts have focused almost exclusively on a handful of prevalent and immunodominant antigens including common targets of neutralizing antibodies $\mathrm{gB}, \mathrm{gH}$, and UL128-131A as well as T-cell epitopes pp65 and IE1. ${ }^{23}$ To elicit potent humoral immunity, gB seems a logical immunogen choice as it is the viral 
fusogen, ${ }^{41}$ is highly immunogenic, is the target of neutralizing antibodies, and is necessary for entry into all cell types. ${ }^{42} \mathrm{gH}$ is also a dominant target of neutralizing antibodies and part of the core viral fusion machinery, ${ }^{41}$ though this neutralization can be strainspecific. $^{43}$ Finally, the UL128/UL130/UL131a proteins, when assembled with the $\mathrm{gH} / \mathrm{gL}$ heterodimer to form the HCMV pentameric complex (PC), is necessary for entry into epithelial cells and is the target of the most potent neutralizing antibodies. ${ }^{44-46}$ The robust potency of neutralizing antibodies targeting UL128-131A makes the PC an attractive vaccine target, and indeed much of the HCMV vaccine field is now focused on targeting these epitopes. ${ }^{47}$ However, there is no indication that the magnitude of neutralization assessed in epithelial cells in vitro has any relationship with protective efficacy in vivo. ${ }^{48,49}$ Presumably, HCMV traverses the placenta by spreading from cell-tocell. ${ }^{50}$ However, there is some disagreement regarding whether PC-specific antibodies can block infection of human placental trophoblasts and thereby prevent cCMV transmission. This process may be influenced by gestational age of the placenta: PC mAbs have been shown to inhibit infection of cytotrophoblasts harvested from term placentas, ${ }^{51}$ but not trophoblast progenitor cells isolated during the first trimester of gestation. ${ }^{52}$

For T-cell epitopes, both pp65 and IE1 have classically been identified as dominant T-cell targets that are present in high frequency in HCMV-seropositive individuals. ${ }^{23}$ Yet, of the 165 proteins encoded by HCMV, 151 have been shown to be targeted by $\mathrm{CD} 4+$ or $\mathrm{CD} 8+\mathrm{T}$ cells. ${ }^{53}$ And it should be noted that the immunodominance of pp65 and IE1-specific T cells does not necessarily reflect the functionality of protective responses, as "subdominant" responses have been shown to be equivalently protective in murine transplant models following adoptive transfer $^{54}$ or DNA vaccination. ${ }^{55}$ More recent analysis of the HCMV-specific CD4 + and CD8 + T-cell repertoire elicited by natural infection suggests that $\mathrm{gB}$ and the $\mathrm{PC}$ are more commonly targeted by CD4 + T cells, IE1 more commonly by CD8 + T cells, and pp65 by both T-cell subsets. ${ }^{56}$

It has long been theorized that an HCMV vaccine might require a multi-antigen approach, incorporating diverse epitopes to optimally engage both humoral and cellular immune factors, thus maximizing the protective immunity elicited. Multi-epitope immune responses can be achieved either through vaccination with a live-attenuated virus or through delivery and/or in vivo expression of a combination of antigens. This approach is not unique to the HCMV vaccine field, as the successful liveattenuated varicella vaccine-elicited responses against many antigens and a diverse array of multivalent vaccine platforms are in development for HSV-1/HSV-2. ${ }^{57-59}$ The most commonly trialed multi-antigen vaccine for HCMV has been the combination of $\mathrm{gB}$ and pp65, either as DNA or co-expressed in a viral vector, which appears safe and highly immunogenic ${ }^{1}$ and has demonstrated additive protection in a guinea pig congenital transmission model. $^{9}$ However, ASP0113, a bivalent DNA vaccine encoding pp65 and gB, did not meet its primary or secondary endpoints in a recent Phase 3 clinical trial of HCMV disease in seropositive hematopoietic stem cell transplant recipients. ${ }^{60}$ Multi-antigen vaccines are logistically challenging to develop ${ }^{61}$ - particularly, if future vaccine candidates seek to incorporate the HCMV PC, which requires that five proteins be manufactured, delivered, expressed, and stabilized in a conformationally accurate manner.

Next-generation, "plug and play" vaccine platforms such as mRNA are well suited to the rapid development of multivalent vaccines, $^{62}$ and can elicit both robust humoral and T-cell immunity. For example, gB, PC, and pp65-encoding mRNA molecules might easily be combined for use in a single vaccine. The antigenicity of multiple HCMV mRNA constructs has been recently evaluated, both alone and in combination, and observed to elicit both robust neutralizing antibody and T-cell responses in mice and nonhuman primates. ${ }^{63}$ Reassuringly, there was no discernable interference in the neutralizing antibody responses elicited by vaccination with a single immunogen vs. multiple immunogens. However, the authors did observe an important phenomenon of T-cell epitope competition, as mRNA coexpression of PC and pp65 resulted in robust CD4 + and CD8 + T-cell responses against $P C$ epitopes, but negligible responses against pp65 epitopes. Yet this competition was able to be overcome by an initial priming vaccination with pp65 alone, followed by co-administration of a pp65 and PC mRNA vaccine. ${ }^{63}$

\section{NEUTRALIZING VS. NON-NEUTRALIZING ANTIBODY RESPONSES}

The elicitation of neutralizing antibodies has been a primary goal of HCMV vaccine research for the past 40 years. ${ }^{23}$ It has been hypothesized that a cCMV vaccine could be efficacious by inducing HCMV-neutralizing antibodies that either: (1) provide sterilizing immunity by inhibiting HCMV acquisition or (2) reduce systemic viral replication, viral seeding of the placenta, and subsequent fetal infection. ${ }^{1}$ Neutralizing antibodies targeting HCMV surface glycoproteins have repeatedly been correlated with reduced incidence of congenital virus transmission after primary $^{26-28}$ and secondary ${ }^{29}$ maternal HCMV infection. Few studies have evaluated any potential role of non-neutralizing antibodies. However, HCMV is a highly cell associated virus ${ }^{64}$ and "immunologically covert" cell-to-cell spread of HCMV is particularly implicated among wild-type clinical strains of HCMV with an intact PC. ${ }^{49}$ It has become increasingly recognized that neutralizing antibodies cannot block cell-to-cell spread of wild-type HCMV. ${ }^{65}$ Thus, non-neutralizing antibodies might provide an additional benefit by inducing complement-mediated virion lysis or by engaging $\mathrm{Fc}$ receptors on immune effector cells that mediate ADCC or antibody-dependent cellular phagocytosis (ADCP). ${ }^{66}$

There is accumulating evidence in the HSV vaccine field that non-neutralizing antibodies may play an important role in vaccinemediated protection, particularly against HSV-2. The magnitude of gD-specific antibodies was correlated with protection against genital HSV-1, but not genital HSV-2 disease in the Herpevac clinical trial ${ }^{18}$ and it is hypothesized that the results may reflect serotype differences in neutralization. ${ }^{67}$ Given that the $\mathrm{gD} /$ AS04 subunit vaccine demonstrated no efficacy against HSV-2 in the Phase 3 field study ${ }^{68}$ a variety of vaccines employing multiple antigenic targets ( $\mathrm{gC}, \mathrm{gD}, \mathrm{gE}$ in combination) have been tested and have met with success in animal models of HSV pathogenesis. ${ }^{69-71}$ Furthermore, Genocea Biosciences tested the GEN-003 vaccine containing both soluble $\mathrm{gD}$ and the ICP4.2 T-cell epitope in phase 2 trials, resulting in a measurable reduction in viral shedding (though comparable to valacyclovir drug therapy). ${ }^{72}$

In contrast, one intriguing new HSV vaccine candidate is an HSV-2 virus deleted for $\mathrm{gD}^{73}$ In the absence of $\mathrm{gD}$, this vaccine (designated $\Delta \mathrm{gD}-2$ ) provided $100 \%$ protection against intravaginal (female) and skin (males and females) challenge with clinical isolates of both HSV-1 and HSV-2. ${ }^{57,74,75}$ Passive transfer studies demonstrated that immune sera alone were sufficient to mediate protection. Importantly, vaccine-elicited antibodies were weakly neutralizing but potently activated Fc-gamma receptors ( $F c \gamma R)$ to mediate ADCC and ADCP. ${ }^{57,74,75}$ Protection was lost in FcyR or FC neonatal receptor knockout mice, indicating a central role for nonneutralizing Abs. ${ }^{57}$ The precise mechanisms by which deletion of an immunodominant viral antigen results in a preferential induction of non-neutralizing antibody responses is under investigation. One hypothesis is that the relative balance of neutralizing and non-neutralizing antibody responses may be regulated, in part, by herpesvirus entry mediator (HVEM), a TNF receptor, and a second-signaling molecule on $\mathrm{B}$ cells, $\mathrm{T}$ cells, and antigen-presenting cells. ${ }^{76} \mathrm{gD}$ competitively binds to HVEM and this interaction may promote the induction of neutralizing or inhibit the generation of non-neutralizing antibodies. In the 
absence of gD, the balance may be shifted. Notably, CMV UL144 binds BTLA, one of the ligands for HVEM, and could potentially modulate immune responses against CMV through a similar pathway. ${ }^{77,78}$ Although the studies with the HSV deletion vaccine are limited to date to small animal models, the notion that ADCC Abs may be important is consistent with prior clinical studies demonstrating that maternally acquired HSV-specific antibodies that mediate ADCC provided greater protection against viral dissemination. ${ }^{79,80}$ Furthermore, data have arisen suggesting the protective efficacy of non-neutralizing antibody responses against other viral pathogens including HIV/SHIV ${ }^{81,82}$ and influenza, ${ }^{83}$ although a combination of neutralizing and non-neutralizing antibody response may be required for optimal protection. Further investigation of $\Delta \mathrm{gD}-2$ and of FcR antibody responses in mediating HSV protection is warranted.

The role of non-neutralizing antibodies in anti-HCMV immunity is gradually being recognized. A recent study examined the ability of neutralizing and non-neutralizing $\mathrm{gB}$-specific antibodies to reduce viral replication in a murine CMV (MCMV) model when given prior to MCMV inoculation (prophylactically) or following MCMV infection (therapeutically). ${ }^{48}$ When given prophylactically, neutralizing antibodies had the greatest therapeutic effect on viral load, though both neutralizing and non-neutralizing antibodies were equally effective in preventing mouse mortality. In addition, we recently identified that non-neutralizing antibodies were likely responsible for the $50 \%$ vaccine efficacy observed in an $\mathrm{HCMV} \mathrm{gB}$ subunit vaccine trial. ${ }^{3,84}$ In previous phase 1 trials, the gB/MF59 vaccine was observed to elicit a high titer of gB-specific antibodies, $^{85}$ though relatively low-level neutralization ${ }^{86}$ that is enhanced in the presence of complement. ${ }^{87}$ Therefore, the induction of neutralizing antibodies has long been thought to be the mechanism of partial vaccine efficacy. However, in a detailed evaluation of the vaccine-elicited responses in a phase 2 trial of postpartum women gB/MF59 vaccinees, ${ }^{3}$ there were no neutralizing responses detectable against heterologous viral strains, suggesting both: (1) a possible difference in the elicitation of neutralizing antibodies in postpartum women compared to healthy, non-recently pregnant individuals and/or (2) that neutralizing antibodies may not have been necessary for the partial vaccine efficacy. ${ }^{84}$

\section{IMMUNOGEN STRUCTURAL DESIGN}

There have been significant advances made in the structural biology of viral fusion proteins over the past decade. The structural models that have emerged have revolutionized the vaccine immunology field by facilitating structure-based vaccine design. ${ }^{88}$ Immunogen conformation has been recognized as an extraordinarily important consideration for $\mathrm{HCMV} \mathrm{gB}$ as well as the $\mathrm{gH} / \mathrm{gL} / \mathrm{UL} 128-131 \mathrm{a}$ PC. $\mathrm{gB}$ is a class III viral fusogen, ${ }^{89}$ and is thus a metastable protein that facilitates merger of the viral envelope and host cell membrane by a conformational change from prefusion and post-fusion states. ${ }^{90,91}$ The post-fusion crystal structure of the protein has been determined, ${ }^{92,93}$ though the pre-fusion form has remained elusive. Following natural infection, some gBspecific antibodies are neutralizing, though the majority are nonneutralizing. ${ }^{94}$ It has been hypothesized that neutralizing antibodies preferentially target epitopes exposed on the pre-fusion form of the protein, and non-neutralizing antibodies those on the post-fusion form. ${ }^{22}$ Indeed, viral metastable expression of both post-fusion and pre-fusion forms of $\mathrm{gB}$ on the virion membrane is proposed as a mechanism of HCMV immune evasion, by which the virus elicits a dominant, non-neutralizing antibody response. ${ }^{92}$ Consistent with this hypothesis, we have previously demonstrated that immunization with soluble post-fusion gB elicited low-level binding responses against neutralizing $\mathrm{gB}$ epitopes in comparison with natural infection, ${ }^{84}$ suggesting that neutralizing epitopes are not adequately exposed to immune cells when $\mathrm{gB}$ is in the postfusion form.

There is a high degree of conservation between HCMV gB and that of HSV and EBV. ${ }^{91,92,95}$ We have a great deal to learn from other herpesvirus fields as HCMV structural biology has lagged behind. The HSV post-fusion crystal structure has been published for well over a decade, ${ }^{96}$ and now have the first hints of a prefusion structure using cryo-electron tomography technology. ${ }^{97,98}$ Furthermore, structure-based mutagenesis techniques have led to the identification of targeted mutations that can prevent the transition from pre-fusion to post-fusion conformation. ${ }^{99} \mathrm{~A}$ stabilized pre-fusion form of the protein will be an indispensable tool for future study. The HCMV vaccine field should utilize these advances to pursue both a pre-fusion structure and a stabilized pre-fusion $\mathrm{gB}$ construct. Moreover, isolation of antibodies specific for this conformation of the protein, would be a tremendous advance for a reverse vaccinology approach to HCMV.

Finally, the structural biology of the $\mathrm{gH} / \mathrm{gL} / \mathrm{UL} 128-131$ a PC is of interest in the HCMV vaccine field. Though extremely potent epithelial cell-neutralizing antibodies are directed against UL128, UL130, and UL131 following natural infection, ${ }^{46}$ immunization with recombinant protein subunits or peptides induces far less potently neutralizing antibodies. ${ }^{100}$ This finding suggests that native folding and assembly of the full complex may be critical for optimal neutralizing antibody responses, ${ }^{23}$ and indeed antibodies have been identified that recognize conformational epitopes only formed by the full PC. ${ }^{46}$ The recently deciphered PC crystal structure ${ }^{101}$ bound to neutralizing antibodies has informed the molecular basis of these conformational epitopes. And wherreas the PC can be expressed in soluble form, ${ }^{102}$ it is unknown how stable this complex is in vivo and thus unknown whether PC subunit vaccination could elicit neutralization titers comparable to natural infection. Thus, many researchers have sought to employ epitope expression strategies such as an MVA vector ${ }^{103}$ or mRNA. ${ }^{63}$

\section{ANTIGENIC DIVERSITY AND BREADTH}

It has long been recognized that HCMV is polymorphic between hosts. ${ }^{104-107}$ With the application of next-generation sequencing technology to HCMV, it has become increasingly apparent that there is extensive, genome-wide antigenic variability between viral strains and even within a single host. ${ }^{108-110}$ The HCMV vaccine field appears to face a somewhat unique challenge in combating this antigenic diversity; among herpesvirus, HCMV boasts far-and-away the highest level of interstrain diversity. ${ }^{111}$ Indeed, HCMV has an overall mean distance (i.e., number of substitution per base pair) of $0.027,{ }^{111}$ which places it in the realm of dengue and other RNA viruses. ${ }^{108}$

Thus, it is perhaps no surprise that antigenic differences have been observed to impact neutralizing antibody responses. In a landmark study, neutralization of HCMV viral isolates was assessed by paired human sera (autologous neutralization) and by the sera of other HCMV-seropositive subjects (heterologous neutralization). ${ }^{112}$ Intriguingly, the authors noted that neutralization antibody titers frequently differed between individuals by an order of magnitude or more, and one viral isolate exhibited complete resistance to heterologous sera antibodies. Indeed, studies of the HCMV and MCMV-specific antibody repertoire have confirmed these findings by identifying $\mathrm{mAbs}$ directed at $\mathrm{gB}$ and $\mathrm{gH}$ that exhibit strain-specific neutralization activity. ${ }^{113,114}$ Thus, antigenic variation will likely be a critical consideration for HCMV vaccine design. Yet it is worth noting that neutralizing antibodies targeting certain conserved epitopes such as gB AD- $2^{94}$ or the UL128/ UL130/UL131a proteins ${ }^{115}$ of the PC do not appear to be strainspecific and have been observed to neutralize genetically diverse HCMV strains. 
We have observed in a cohort of gB/MF59-vaccinated postpartum women from a phase 2 vaccine efficacy study ${ }^{3}$ that neutralizing antibodies were only detectable against a virus containing the vaccine strain of $\mathrm{gB}$ (Towne), though not against heterologous strains AD169 and TB40/E. ${ }^{84}$ However, heterologous neutralizing antibodies were measurable in a cohort of phase 1 healthy adult gB/MF59 vaccinees, suggesting that patient population may impact the breadth of neutralizing antibodies elicited by $\mathrm{gB} / \mathrm{MF} 59$ vaccination.

\section{GLYCAN SHIELDING AND DECOY EPITOPES}

The purpose of viral envelope protein glycosylation remains poorly understood, though has been described to either: (1) enhance viral immune evasion or (2) facilitate critical viral processes including cellular entry and/or protein processing. ${ }^{116}$ Glycan shielding of susceptible epitopes is a strategy known to be employed by HIV-1 and influenza, ${ }^{116}$ and perhaps also by HCMV. ${ }^{117,118}$ The mutation of highly conserved glycan sites in HCMV gN dramatically enhances viral susceptibility to neutralizing antibodies-including nAbs targeting glycoproteins other than $\mathrm{gN}^{118}$ The structures of $\mathrm{HCMV} \mathrm{gB}^{92}$ and the pentameric complex ${ }^{101}$ primary targets of neutralizing antibodies, are both heavily glycosylated. Of particular note, for both $\mathrm{gB}$ and the PC, neutralizing epitopes are enriched with highly conserved $\mathrm{N}$-linked glycan sites, ${ }^{93,119}$ suggesting that glycans might play a role in preventing antigenic recognition of these susceptible sites. HCMV gB in particular has $18 \mathrm{~N}$-linked glycan sites, markedly more than the homologous protein in either HSV-1 or EBV. By careful manipulation of patterns of glycan shielding, it is anticipated that HCMV can elicit a predominantly non-neutralizing anti-gB response profile. For example, heavy glycosylation of the AD-4 and AD-5 regions known to be targeted by neutralizing antibodies $^{94}$ yet sparse glycosylation of predominantly nonneutralizing AD-1 might explain why non-neutralizing AD-1specific antibodies are the most dominant gB-specific antibody response observed following natural infection. ${ }^{92}$ An alternative hypothesis to glycan shielding is that viral envelope protein glycans can interact with inhibitory immune cell receptors, and thus might modulate either MHC presentation or B-cell activation pathways, ${ }^{120}$ though there are no data to support this theory for herpesvirus pathogens. Although the impact of HCMV envelope protein glycosylation on neutralizing antibody recognition of susceptible epitopes is currently theoretical, it will be an important consideration for future vaccine design efforts.

Analogously to glycan shielding, an immune-dominant decoy response elicited upon vaccination can divert and limit functional immunity against a pathogen. This phenomenon has been described for several viruses, including HIV-1 and HSV. In one HIV vaccine study, ${ }^{121} 93 \%$ of the HIV-specific B-cell response was observed against gp41-a protein subunit located proximally to the virion membrane and most frequently targeted by nonneutralizing antibodies. ${ }^{122}$ Similarly, in the HSV field, gD subunit vaccines have long been the focus of vaccine development owing to the immune-dominance of this antigen following natural infection, yet they have had limited success in clinical trial. ${ }^{68}$ Thus, it was hypothesized that gD-specific antibodies, though potently neutralizing, may be a decoy immune response that can block the development of more potently functional antibodies. Subsequently, it was observed that a gD-deletion live-attenuated vaccine can elicit robust, protective, non-neutralizing antibody responses. ${ }^{57,74,75}$

Similarly, we recently assessed the epitope specificity of antibodies elicited by gB/MF59 vaccination in the most efficacious HCMV vaccine trial to date. ${ }^{84}$ Using a peptide microarray covering the full gB open-reading frame, we identified that the gB/MF59 vaccine induced an extraordinarily high-magnitude response against peptide epitopes within the cytosolic gB AD-3 region, a known non-neutralizing epitope. ${ }^{92}$ Indeed, $76 \%$ of vaccine-elicited linear gB-binding was directed against the AD-3 epitope, in comparison to $31 \%$ in naturally HCMV-infected individuals. As we also observed that this vaccine elicited: (1) very low neutralizing antibody responses and (2) poor targeting of known neutralizing epitopes, we hypothesize that the dominant AD-3-specific antibody response may have diverted functional antibodies away from neutralization-susceptible sites (Fig. 1).

\section{FINAL SUMMARY}

There is an accumulating body of evidence that $\mathrm{HCMV}$ vaccination can influence the incidence of infection and congenital disease. There are still numerous questions to be answered and hurdles to

\begin{tabular}{|c|c|c|c|c|c|}
\hline $\begin{array}{l}\text { Immune response } \\
\text { characteristic / viral } \\
\text { evasion mechanism }\end{array}$ & $\begin{array}{l}\text { HCMV } \\
\text { (HHV-5) }\end{array}$ & $\begin{array}{l}\text { HSV-1 } \\
\text { (HHV-1) }\end{array}$ & $\begin{array}{c}\text { HSV-2 } \\
(H H V-2)\end{array}$ & $\begin{array}{l}\text { VZV } \\
(H H V-3)\end{array}$ & $\begin{array}{l}\text { EBV } \\
(H H V-4)\end{array}$ \\
\hline Humoral immunity & $\begin{array}{c}11,25- \\
31,39,48,84,123\end{array}$ & $18,67,124-126$ & $\begin{array}{c}57,58,74,75,79 \\
80,127\end{array}$ & $12-14,128-130$ & 19,131 \\
\hline Cellular immunity & $33,34,39$ & 132,133 & 134 & $135-137$ & $138-141$ \\
\hline $\begin{array}{c}\text { Multiple antigenic } \\
\text { targets }\end{array}$ & $8,9,142$ & 143 & $\begin{array}{c}57,59,69,74,75 \\
144-146\end{array}$ & 12,13 & $138-141$ \\
\hline $\begin{array}{c}\text { Neutralizing } \\
\text { antibodies }\end{array}$ & $11,25-31,39,48$ & $67,124-126$ & 127 & 147 & 19,131 \\
\hline $\begin{array}{c}\text { Non-neutralizing } \\
\text { antibodies }\end{array}$ & 48,84 & & $57,74,75,79,80$ & & 148 \\
\hline $\begin{array}{c}\text { Conformation- } \\
\text { dependent epitopes }\end{array}$ & $91,100,119$ & 97,98 & & & 149 \\
\hline $\begin{array}{c}\text { Viral antigenic } \\
\text { diversity }\end{array}$ & $111-114$ & 150 & & & 151 \\
\hline $\begin{array}{c}\text { Glycan shielding of } \\
\text { viral epitopes }\end{array}$ & 101,119 & & & & \\
\hline Decoy viral epitopes & 84 & & $57,74,75$ & & \\
\hline
\end{tabular}

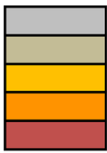
Fig. 1 Evidence for virus-specific immune response characteristics and viral immune evasion mechanisms in control of herpesvirus replication
and/or prevention of disease. References cited in this figure are: $8,9,11-14,18,19,25-31,33,34,39,48,57-59,67,69,74,75,79,80,84,91,97,98,100,101,111,114,119,123-151$ 
be to overcome in HCMV vaccine development; yet interest in the field among both public and private sector researchers has blossomed over the past decade, as evidenced by the number vaccine candidates entering clinical evaluation. ${ }^{1}$ Thus, the future of the HCMV vaccine field is bright, with hope for unique vaccine designs that will bring an end to this common and devastating disease of pediatric and immune-suppressed populations. ${ }^{123-151}$

\section{ACKNOWLEDGEMENTS}

This work was supported by: NIH/NICHD Director's New Innovator grant to S.R.P. (DP2HD075699), NIH/NIAID R21 to S.R.P. (R21AI136556), NIH/NICHD F30 grant to C.S. N. (F30HD089577), and NIH/NIAID R01 to B.C.H (R01Al117321). The funders had no role in the decision to publish or preparation of this manuscript. The content is solely the responsibility of the authors and does not necessarily represent the official views of the National Institutes of Health.

\section{AUTHOR CONTRIBUTIONS}

All authors researched, collated, and wrote this paper.

\section{ADDITIONAL INFORMATION}

Competing interests: S.R.P. provides consulting services to Pfizer Inc., Merck, and Moderna for their preclinical HCMV vaccine programs. B.C.H. is an inventor on a pending patent application for a delta $\mathrm{gD}-2$ vaccine. The other authors have no conflicts of interest to declare.

Publisher's note: Springer Nature remains neutral with regard to jurisdictional claims in published maps and institutional affiliations.

\section{REFERENCES}

1. Schleiss, M. R. Cytomegalovirus vaccines under clinical development. J. Virus Erad. 2, 198-207 (2016)

2. Bernstein, D. I. et al. Safety and efficacy of a cytomegalovirus glycoprotein B (gB) vaccine in adolescent girls: a randomized clinical trial. Vaccine 34, 313-319 (2016).

3. Pass, R. F. et al. Vaccine prevention of maternal cytomegalovirus infection. $N$. Engl. J. Med. 360, 1191-1199 (2009)

4. Britt, W. J. Congenital human cytomegalovirus infection and the enigma of maternal immunity. J. Virol. 91, pii: e02392-16 (2017).

5. Griffiths, P. D. et al. Cytomegalovirus glycoprotein-B vaccine with MF59 adjuvant in transplant recipients: a phase 2 randomised placebo-controlled trial. Lancet 377, 1256-1263 (2011).

6. Schleiss, M. R. et al. Protection against congenital cytomegalovirus infection and disease in guinea pigs, conferred by a purified recombinant glycoprotein B vaccine. J. Infect. Dis. 189, 1374-1381 (2004).

7. Crumpler, M. M., Choi, K. Y., McVoy, M. A. \& Schleiss, M. R. A live guinea pig cytomegalovirus vaccine deleted of three putative immune evasion genes is highly attenuated but remains immunogenic in a vaccine/challenge model of congenital cytomegalovirus infection. Vaccine 27, 4209-4218 (2009).

8. Schleiss, M. R. et al. Vaccination with a live attenuated cytomegalovirus devoid of a protein kinase $\mathrm{R}$ inhibitory gene results in reduced maternal viremia and improved pregnancy outcome in a guinea pig congenital infection model. J. Virol. 89, 9727-9738 (2015).

9. Schleiss, M. R. et al. Additive protection against congenital cytomegalovirus conferred by combined glycoprotein B/pp65 vaccination using a lymphocytic choriomeningitis virus vector. Clin. Vaccine Immunol. 24, e00300-16 (2017).

10. Auerbach, M. R. et al. A neutralizing anti-gH/gL monoclonal antibody is protective in the guinea pig model of congenital CMV infection. PLoS Pathog. 10, e1004060 (2014).

11. Nelson, C. S. et al. Preexisting antibodies can protect against congenital cytomegalovirus infection in monkeys. JCI Insight 2, pii: 94002 (2017).

12. Krause, P. R. \& Klinman, D. M. Efficacy, immunogenicity, safety, and use of liveattenuated chickenpox vaccine. J. Pediatr. 127, 518-525 (1995).

13. Oxman, M. N. et al. A vaccine to prevent herpes zoster and postherpetic neuralgia in older adults. N. Engl. J. Med. 352, 2271-2284 (2005),

14. Lal, H., Cunningham, A. L. \& Heineman, T. C. Adjuvanted herpes Zoster subunit vaccine in older adults. N. Engl. J. Med. 373, 1576-1577 (2015).

15. Cunningham, A. L. et al. Immune responses to a recombinant glycoprotein $E$ herpes zoster vaccine in adults aged $>/=50$ years. J. Infect. Dis. 217, 1750-1760 (2018)
16. Raaperi, K., Orro, T. \& Viltrop, A. Epidemiology and control of bovine herpesvirus 1 infection in Europe. Vet. J. 201, 249-256 (2014).

17. Stanberry, L. R. et al. Glycoprotein-D-adjuvant vaccine to prevent genital herpes. N. Engl. J. Med. 347, 1652-1661 (2002).

18. Belshe, R. B. et al. Correlate of immune protection against HSV-1 genital disease in vaccinated women. J. Infect. Dis. 209, 828-836 (2014).

19. Sokal, E. M. et al. Recombinant gp350 vaccine for infectious mononucleosis: a phase 2, randomized, double-blind, placebo-controlled trial to evaluate the safety, immunogenicity, and efficacy of an Epstein-Barr virus vaccine in healthy young adults. J. Infect. Dis. 196, 1749-1753 (2007).

20. Colugnati, F. A., Staras, S. A., Dollard, S. C. \& Cannon, M. J. Incidence of cytomegalovirus infection among the general population and pregnant women in the United States. Bmc. Infect. Dis. 7, 71 (2007).

21. Plotkin, S. A. Vaccination against cytomegalovirus, the changeling demon. Pediatr. Infect. Dis. J. 18, 313-325 (1999). quiz 326.

22. Manicklal, S., Emery, V. C., Lazzarotto, T., Boppana, S. B. \& Gupta, R. K. The "silent" global burden of congenital cytomegalovirus. Clin. Microbiol. Rev. 26, 86-102 (2013).

23. Reddehase, M. J. \& Lemmermann, N. Cytomegaloviruses: from molecular pathogenesis to intervention. Emerg. Infect. Dis. 2013;19:1906.

24. Sabbaj, S., Pass, R. F., Goepfert, P. A. \& Pichon, S. Glycoprotein B vaccine is capable of boosting both antibody and CD4 T-cell responses to cytomegalovirus in chronically infected women. J. Infect. Dis. 203, 1534-1541 (2011).

25. Baraniak, l. et al. Epitope-specific humoral responses to human cytomegalovirus glycoprotein-B vaccine with MF59: anti-AD2 levels correlate with protection from viremia. J. Infect. Dis. 217, 1907-1917 (2018).

26. Lilleri, D., Kabanova, A., Lanzavecchia, A. \& Gerna, G. Antibodies against neutralization epitopes of human cytomegalovirus $\mathrm{gH} / \mathrm{gL} / \mathrm{pUL} 128-130-131$ complex and virus spreading may correlate with virus control in vivo. J. Clin. Immunol. 32, 1324-1331 (2012).

27. Lilleri, D. et al. Fetal human cytomegalovirus transmission correlates with delayed maternal antibodies to $\mathrm{gH} / \mathrm{gL} / \mathrm{pUL} 128-130-131$ complex during primary infection. PLOS ONE 8, e59863 (2013).

28. Boppana, S. B. \& Britt, W. J. Antiviral antibody responses and intrauterine transmission after primary maternal cytomegalovirus infection. J. Infect. Dis. 171, 1115-1121 (1995).

29. Bialas, K. M. et al. Maternal antibody responses and nonprimary congenital cytomegalovirus infection of HIV-1-exposed infants. J. Infect. Dis. 214, 1916-1923 (2016).

30. Nigro, G., Adler, S. P., La Torre, R., \& Best, A. M. Congenital Cytomegalovirus Collaborating. Passive immunization during pregnancy for congenital cytomegalovirus infection. N. Engl. J. Med. 353, 1350-1362 (2005).

31. Nigro, G. et al. Immunoglobulin therapy of fetal cytomegalovirus infection occurring in the first half of pregnancy-a case-control study of the outcome in children. J. Infect. Dis. 205, 215-227 (2012).

32. Revello, M. G. et al. A randomized trial of hyperimmune globulin to prevent congenital cytomegalovirus. N. Engl. J. Med. 370, 1316-1326 (2014).

33. Lilleri, D. et al. Development of human cytomegalovirus-specific T cell immunity during primary infection of pregnant women and its correlation with virus transmission to the fetus. J. Infect. Dis. 195, 1062-1070 (2007).

34. Fornara, C., Furione, M., Arossa, A., Gerna, G. \& Lilleri, D. Comparative magnitude and kinetics of human cytomegalovirus-specific CD4 $(+)$ and $\operatorname{CD} 8(+)$ T-cell responses in pregnant women with primary versus remote infection and in transmitting versus non-transmitting mothers: Its utility for dating primary infection in pregnancy. J. Med. Virol. 88, 1238-1246 (2016).

35. Hook, L. M. et al. Vaccine-induced antibodies to herpes simplex virus glycoprotein $\mathrm{D}$ epitopes involved in virus entry and cell-to-cell spread correlate with protection against genital disease in guinea pigs. PLoS Pathog. 14, e1007095 (2018).

36. Kuter, B. J. et al. Oka/Merck varicella vaccine in healthy children: final report of a 2-year efficacy study and 7-year follow-up studies. Vaccine 9, 643-647 (1991).

37. Weinberg, A., Enomoto, L., Marcus, R. \& Canniff, J. Effect of menstrual cycle variation in female sex hormones on cellular immunity and regulation. J. Reprod. Immunol. 89, 70-77 (2011).

38. Leroux-Roels, I. et al. A phase $1 / 2$ clinical trial evaluating safety and immunogenicity of a varicella zoster glycoprotein e subunit vaccine candidate in young and older adults. J. Infect. Dis. 206, 1280-1290 (2012).

39. Bialas, K. M. et al. Maternal $C D 4+T$ cells protect against severe congenital cytomegalovirus disease in a novel nonhuman primate model of placental cytomegalovirus transmission. Proc. Natl. Acad. Sci. 112, 13645-13650 (2015).

40. Murphy, E. et al. Coding potential of laboratory and clinical strains of human cytomegalovirus. Proc. Natl. Acad. Sci. USA 100, 14976-14981 (2003).

41. Vanarsdall, A. L., Ryckman, B. J., Chase, M. C. \& Johnson, D. C. Human cytomegalovirus glycoproteins $\mathrm{gB}$ and $\mathrm{gH} / \mathrm{gL}$ mediate epithelial cell-cell fusion when expressed either in cis or in trans. J. Virol. 82, 11837-11850 (2008). 
42. Isaacson, M. K. \& Compton, T. Human cytomegalovirus glycoprotein B is required for virus entry and cell-to-cell spread but not for virion attachment, assembly, or egress. J. Virol. 83, 3891-3903 (2009).

43. Boppana, S. B., Rivera, L. B., Fowler, K. B., Mach, M. \& Britt, W. J. Intrauterine transmission of cytomegalovirus to infants of women with preconceptional immunity. N. Engl. J. Med. 344, 1366-1371 (2001).

44. Hahn, G. et al. Human cytomegalovirus UL131-128 genes are indispensable for virus growth in endothelial cells and virus transfer to leukocytes. J. Virol. 78, 10023-10033 (2004)

45. Wang, D. \& Shenk, T. Human cytomegalovirus virion protein complex required for epithelial and endothelial cell tropism. Proc. Natl. Acad. Sci. USA 102, 18153-18158 (2005).

46. Macagno, A. et al. Isolation of human monoclonal antibodies that potently neutralize human cytomegalovirus infection by targeting different epitopes on the $\mathrm{gH} / \mathrm{gL} / \mathrm{UL} 128-131 \mathrm{~A}$ complex. J. Virol. 84, 1005-1013 (2010).

47. Anderholm, K. M., Bierle, C. J. \& Schleiss, M. R. Cytomegalovirus vaccines: current status and future prospects. Drugs 76, 1625-1645 (2016).

48. Bootz, A. et al. Protective capacity of neutralizing and non-neutralizing antibodies against glycoprotein B of cytomegalovirus. PLoS Pathog. 13, e1006601 (2017).

49. Murrell, I. et al. The pentameric complex drives immunologically covert cell-cell transmission of wild-type human cytomegalovirus. Proc. Natl. Acad. Sci. USA 114, 6104-6109 (2017).

50. Pereira, L., Petitt, M. \& Tabata, T. Cytomegalovirus infection and antibody protection of the developing placenta. Clin. Infect. Dis. 57, S174-177 (2013).

51. Chiuppesi, F. et al. Vaccine-derived neutralizing antibodies to the human cytomegalovirus $\mathrm{gH} / \mathrm{gL}$ pentamer potently block primary cytotrophoblast infection. J. Virol. 89, 11884-11898 (2015).

52. Zydek, M. et al. HCMV infection of human trophoblast progenitor cells of the placenta is neutralized by a human monoclonal antibody to glycoprotein B and not by antibodies to the pentamer complex. Viruses 6, 1346-1364 (2014).

53. Sylwester, A. W. et al. Broadly targeted human cytomegalovirus-specific CD4+ and CD8 + T cells dominate the memory compartments of exposed subjects. $J$ Exp. Med. 202, 673-685 (2005)

54. Holtappels, R. et al. The putative natural killer decoy early genem04 (gp34) of murine cytomegalovirus encodes an antigenic peptide recognized by protective antiviral CD8 T cells. J. Virol. 74, 1871-1884 (2000).

55. Morello, C. S., Ye, M. \& Spector, D. H. Development of a vaccine against murine cytomegalovirus (MCMV), consisting of plasmid DNA and formalin-inactivated MCMV, that provides long-term, complete protection against viral replication. J. Virol. 76, 4822-4835 (2002).

56. Lilleri, D. \& Gerna, G. Maternal immune correlates of protection from human cytomegalovirus transmission to the fetus after primary infection in pregnancy. Rev. Med. Virol. 27, https://doi.org/10.1002/rmv.1921 (2017).

57. Petro, C. et al. Herpes simplex type 2 virus deleted in glycoprotein D protects against vaginal, skin and neural disease. Elife 4, https://doi.org/10.7554/ eLife.06054 (2015)

58. Halford, W. P., Geltz, J., Messer, R. J. \& Hasenkrug, K. J. Antibodies are required for complete vaccine-induced protection against herpes simplex virus 2. PLOS ONE 10, e0145228 (2015)

59. Awasthi, S. \& Friedman, H. M. Status of prophylactic and therapeutic genital herpes vaccines. Curr. Opin. Virol. 6, 6-12 (2014).

60. Incorporated, V. Astellas and Vical Announce Top-Line Results for Phase 3 Trial of Cytomegalovirus Vaccine ASP0113 in Hematopoietic Stem Cell Transplant Recipients http://www.vical.com/investors/news-releases/News-Release-Details/ 2018/Astellas-and-Vical-Announce-Top-Line-Results-for-Phase-3-Trial-ofCytomegalovirus-Vaccine-ASP0113--in-Hematopoietic-Stem-Cell-TransplantRecipients/default.aspx (2018).

61. Vidor, E. The nature and consequences of intra- and inter-vaccine interference. J. Comp. Pathol. 137, S62-66 (2007).

62. Pardi, N., Hogan, M. J., Porter, F. W., \& Weissman, D. mRNA vaccines - a new era in vaccinology. Nat. Rev. Drug. Discov. 17, 261-279 (2018)

63. John, S. et al. Multi-antigenic human cytomegalovirus mRNA vaccines that elicit potent humoral and cell-mediated immunity. Vaccine 36, 1689-1699 (2018).

64. Silva, M. C., Schroer, J. \& Shenk, T. Human cytomegalovirus cell-to-cell spread in the absence of an essential assembly protein. Proc. Natl. Acad. Sci. USA 102, 2081-2086 (2005).

65. Jacob, C. L. et al. Neutralizing antibodies are unable to inhibit direct viral cell-tocell spread of human cytomegalovirus. Virology 444, 140-147 (2013).

66. Lu, L. L., Suscovich, T. J., Fortune, S. M. \& Alter, G. Beyond binding: antibody effector functions in infectious diseases. Nat. Rev. Immunol. 18, 46-61 (2018).

67. Awasthi, S., Belshe, R. B. \& Friedman, H. M. Better neutralization of herpes simplex virus type 1 (HSV-1) than HSV-2 by antibody from recipients of GlaxoSmithKline HSV-2 glycoprotein D2 subunit vaccine. J. Infect. Dis. 210, 571-575 (2014).
68. Belshe, R. B. et al. Efficacy results of a trial of a herpes simplex vaccine. N. Engl. J. Med. 366, 34-43 (2012).

69. Awasthi, S. et al. An HSV-2 trivalent vaccine is immunogenic in rhesus macaques and highly efficacious in guinea pigs. PLoS Pathog. 13, e1006141 (2017).

70. Awasthi, S. et al. Protection provided by a herpes simplex virus 2 (HSV-2) glycoprotein $C$ and D subunit antigen vaccine against genital HSV-2 infection in HSV-1-seropositive guinea pigs. J. Virol. 88, 2000-2010 (2014).

71. Awasthi, S. et al. Immunization with a vaccine combining herpes simplex virus 2 (HSV-2) glycoprotein $\mathrm{C}(\mathrm{gC})$ and $\mathrm{gD}$ subunits improves the protection of dorsal root ganglia in mice and reduces the frequency of recurrent vaginal shedding of HSV-2 DNA in guinea pigs compared to immunization with gD alone. J. Virol. 85 , 10472-10486 (2011).

72. Bernstein, D. I. et al. Therapeutic vaccine for genital herpes simplex virus-2 infection: findings from a randomized trial. J. Infect. Dis. 215, 856-864 (2017).

73. Corey, L. et al. Recombinant glycoprotein vaccine for the prevention of genital HSV-2 infection: two randomized controlled trials. Chiron HSV Vaccine Study Group. JAMA 282, 331-340 (1999).

74. Petro, C. D. et al. HSV-2 DeltagD elicits FcgammaR-effector antibodies that protect against clinical isolates. JCI Insight 1, e88529 (2016).

75. Burn, C. et al. A herpes simplex virus (HSV)-2 single-cycle candidate vaccine deleted in glycoprotein $D$ protects male mice from lethal skin challenge with clinical isolates of HSV-1 and HSV-2. J. Infect. Dis. 217, 754-758 (2018).

76. Cheung, T. C. et al. Unconventional ligand activation of herpesvirus entry mediator signals cell survival. Proc. Natl. Acad. Sci. USA 106, 6244-6249 (2009).

77. Cheung, T. C. et al. Evolutionarily divergent herpesviruses modulate $T$ cell activation by targeting the herpesvirus entry mediator cosignaling pathway. Proc. Natl. Acad. Sci. USA 102, 13218-13223 (2005).

78. Marsters, S. A. et al. Herpesvirus entry mediator, a member of the tumor necrosis factor receptor (TNFR) family, interacts with members of the TNFR-associated factor family and activates the transcription factors NF-kappaB and AP-1. J. Biol. Chem. 272, 14029-14032 (1997).

79. Kohl, S. et al. Neonatal antibody-dependent cellular cytotoxic antibody levels are associated with the clinical presentation of neonatal herpes simplex virus infection. J. Infect. Dis. 160, 770-776 (1989).

80. Kohl, S. Role of antibody-dependent cellular cytotoxicity in neonatal infection with herpes simplex virus. Rev. Infect. Dis. 13, S950-952 (1991).

81. Bonsignori, M. et al. Antibody-dependent cellular cytotoxicity-mediating antibodies from an HIV-1 vaccine efficacy trial target multiple epitopes and preferentially use the VH1 gene family. J. Virol. 86, 11521-11532 (2012).

82. Florese, R. H. et al. Contribution of nonneutralizing vaccine-elicited antibody activities to improved protective efficacy in rhesus macaques immunized with Tat/Env compared with multigenic vaccines. J. Immunol. 182, 3718-3727 (2009).

83. DiLillo, D. J., Tan, G. S., Palese, P. \& Ravetch, J. V. Broadly neutralizing hemagglutinin stalk-specific antibodies require FcgammaR interactions for protection against influenza virus in vivo. Nat. Med. 20, 143-151 (2014).

84. Nelson, C. S. et al. HCMV glycoprotein B subunit vaccine efficacy mediated by nonneutralizing antibody effector functions. Proc. Natl. Acad. Sci. USA 115, 6267-6272 (2018).

85. Pass, R. F. et al. A subunit cytomegalovirus vaccine based on recombinant envelope glycoprotein B and a new adjuvant. J. Infect. Dis. 180, 970-975 (1999).

86. Cui, X., Meza, B. P., Adler, S. P. \& McVoy, M. A. Cytomegalovirus vaccines fail to induce epithelial entry neutralizing antibodies comparable to natural infection. Vaccine 26, 5760-5766 (2008).

87. Li, F. et al. Complement enhances in vitro neutralizing potency of antibodies to human cytomegalovirus glycoprotein $\mathrm{B}(\mathrm{gB})$ and immune sera induced by $\mathrm{gB} /$ MF59 vaccination. NPJ Vaccines 2, 36 (2017).

88. Kulp, D. W. \& Schief, W. R. Advances in structure-based vaccine design. Curr Opin. Virol. 3, 322-331 (2013).

89. Backovic, M. \& Jardetzky, T. S. Class III viral membrane fusion proteins. Curr. Opin. Struct. Biol. 19, 189-196 (2009).

90. Harrison, S. C. Viral membrane fusion. Virology 479-480, 498-507 (2015).

91. Cooper, R. S. \& Heldwein, E. E. Herpesvirus gB: a finely tuned fusion machine. Viruses 7, 6552-6569 (2015).

92. Burke, H. G. \& Heldwein, E. E. Correction: crystal structure of the human cytomegalovirus glycoprotein B. PLoS Pathog. 11, e1005300 (2015).

93. Chandramouli, S. et al. Structure of HCMV glycoprotein B in the postfusion conformation bound to a neutralizing human antibody. Nat. Commun. 6, 8176 (2015).

94. Potzsch, S. et al. B cell repertoire analysis identifies new antigenic domains on glycoprotein B of human cytomegalovirus which are target of neutralizing antibodies. PLoS Pathog. 7, e1002172 (2011).

95. Ratta, B., Yadav, B. S., Pokhriyal, M., Saxena, M. \& Sharma, B. Microarray chip based identification of a mixed infection of bovine herpesvirus 1 and bovine viral diarrhea 2 from Indian cattle. Curr. Microbiol. 68, 127-131 (2014). 
96. Heldwein, E. E. et al. Crystal structure of glycoprotein B from herpes simplex virus 1. Science 313, 217-220 (2006).

97. Zeev-Ben-Mordehai, T. et al. Two distinct trimeric conformations of natively membrane-anchored full-length herpes simplex virus 1 glycoprotein B. Proc. Natl. Acad. Sci. USA 113, 4176-4181 (2016).

98. Fontana, J. et al. The fusion loops of the initial prefusion conformation of herpes simplex virus 1 fusion protein point toward the membrane. mBio 8, pii: e0126817 (2017).

99. Fan, Q., Kopp, S., Connolly, S. A., Muller, W. J. \& Longnecker, R. Mapping sites of herpes simplex virus type 1 glycoprotein $D$ that permit insertions and impact gD and gB receptors usage. Sci. Rep. 7, 43712 (2017).

100. Saccoccio, F. M. et al. Peptides from cytomegalovirus UL130 and UL131 proteins induce high titer antibodies that block viral entry into mucosal epithelial cells. Vaccine 29, 2705-2711 (2011)

101. Chandramouli, S. et al. Structural basis for potent antibody-mediated neutralization of human cytomegalovirus. Sci. Immunol. 2, pii: eaan1457 (2017).

102. Loughney, J. W. et al. Soluble human cytomegalovirus $\mathrm{gH} / \mathrm{gL} / \mathrm{pUL} 128-131$ pentameric complex, but Not $\mathrm{gH} / \mathrm{gL}$, inhibits viral entry to epithelial cells and presents dominant native neutralizing epitopes. J. Biol. Chem. 290, 15985-15995 (2015).

103. Wussow, F. et al. Human cytomegalovirus vaccine based on the envelope $\mathrm{gH} / \mathrm{gL}$ pentamer complex. PLoS Pathog. 10, e1004524 (2014).

104. Bradley, A. J. et al. Genotypic analysis of two hypervariable human cytomegalovirus genes. J. Med. Virol. 80, 1615-1623 (2008).

105. Coaquette, A. et al. Mixed cytomegalovirus glycoprotein B genotypes in immunocompromised patients. Clin. Infect. Dis. 39, 155-161 (2004).

106. Hassan-Walker, A. F., Okwuadi, S., Lee, L., Griffiths, P. D. \& Emery, V. C. Sequence variability of the alpha-chemokine UL146 from clinical strains of human cytomegalovirus. J. Med. Virol. 74, 573-579 (2004)

107. Murthy, S. et al. Detection of a single identical cytomegalovirus (CMV) strain in recently seroconverted young women. PLOS ONE 6, e15949 (2011).

108. Renzette, N., Bhattacharjee, B., Jensen, J. D., Gibson, L. \& Kowalik, T. F. Extensive genome-wide variability of human cytomegalovirus in congenitally infected infants. PLoS Pathog. 7, e1001344 (2011).

109. Renzette, N. et al. Rapid intrahost evolution of human cytomegalovirus is shaped by demography and positive selection. PLoS. Genet. 9, e1003735 (2013).

110. Renzette, N. et al. Limits and patterns of cytomegalovirus genomic diversity in humans. Proc. Natl. Acad. Sci. USA 112, E4120-4128 (2015).

111. Sijmons, S. et al. High-throughput analysis of human cytomegalovirus genome diversity highlights the widespread occurrence of gene-disrupting mutations and pervasive recombination. J. Virol. https://doi.org/10.1128/JVI.00578-15 (2015).

112. Klein, M., Schoppel, K., Amvrossiadis, N. \& Mach, M. Strain-specific neutralization of human cytomegalovirus isolates by human sera. J. Virol. 73, 878-886 (1999).

113. Baboonian, C., Blake, K., Booth, J. C. \& Wiblin, C. N. Complement-independent neutralising monoclonal antibody with differential reactivity for strains of human cytomegalovirus. J. Med. Virol. 29, 139-145 (1989).

114. Simpson, J. A. et al. Neutralizing monoclonal antibodies that distinguish three antigenic sites on human cytomegalovirus glycoprotein $\mathrm{H}$ have conformationally distinct binding sites. J. Virol. 67, 489-496 (1993).

115. $\mathrm{Ha}$, S. et al. Neutralization of diverse human cytomegalovirus strains conferred by antibodies targeting viral gH/gL/pUL128-131 pentameric complex. J. Virol. 91, pii: e02033-16 (2017)

116. Vigerust, D. J. \& Shepherd, V. L. Virus glycosylation: role in virulence and immune interactions. Trends Microbiol. 15, 211-218 (2007).

117. Gardner, T. J. \& Tortorella, D. Virion glycoprotein-mediated immune evasion by human cytomegalovirus: a sticky virus makes a slick getaway. Microbiol. Mol. Biol. Rev. 80, 663-677 (2016).

118. Kropff, B. et al. Glycoprotein N of human cytomegalovirus protects the virus from neutralizing antibodies. PLoS Pathog. 8, e1002999 (2012).

119. Burke, H. G. \& Heldwein, E. E. Crystal structure of the human cytomegalovirus glycoprotein B. PLoS Pathog. 11, e1005227 (2015).

120. Wolfert, M. A. \& Boons, G. J. Adaptive immune activation: glycosylation does matter. Nat. Chem. Biol. 9, 776-784 (2013)

121. Hammer, S. M. et al. Efficacy trial of a DNA/rAd5 HIV-1 preventive vaccine. $N$. Engl. J. Med. 369, 2083-2092 (2013).

122. Williams, W. B. et al. HIV-1 Vaccines. Diversion of HIV-1 vaccine-induced immunity by gp41-microbiota cross-reactive antibodies. Science 349, aab1253 (2015).

123. Bialas, K. M., Westreich, D., Cisneros de la Rosa, E., Nelson, C., Kauvar, L. M., Fu, T.M. \& Permar, S. Maternal antibody responses and nonprimary congenital cytomegalovirus infection of HIV-1 exposed infants. J.Infect. Dis. 214, 1916-1923 (2016)
124. Awasthi, S. \& Friedman, H. M. A paradigm shift: vaccine-induced antibodies as an immune correlate of protection against herpes simplex virus type 1 genital herpes. J. Infect. Dis. 209, 813-815 (2014).

125. Dix, R. D., Pereira, L. \& Baringer, J. R. Use of monoclonal antibody directed against herpes simplex virus glycoproteins to protect mice against acute virusinduced neurological disease. Infect. Immun. 34, 192-199 (1981).

126. Ghiasi, H., Wechsler, S. L., Cai, S., Nesburn, A. B. \& Hofman, F. M. The role of neutralizing antibody and T-helper subtypes in protection and pathogenesis of vaccinated mice following ocular HSV-1 challenge. Immunology 95, 352-359 (1998).

127. Balachandran, N., Bacchetti, S. \& Rawls, W. E. Protection against lethal challenge of BALB/c mice by passive transfer of monoclonal antibodies to five glycoproteins of herpes simplex virus type 2 . Infect. Immun. 37, 1132-1137 (1982).

128. Gilbert, P. B. et al. Fold rise in antibody titers by measured by glycoproteinbased enzyme-linked immunosorbent assay is an excellent correlate of protection for a herpes zoster vaccine, demonstrated via the vaccine efficacy curve. J. Infect. Dis. 210(10), 1573-1581 (2014).

129. Michalik, D. E. et al. Primary vaccine failure after 1 dose of varicella vaccine in healthy children. J. Infect. Dis. 197, 944-949 (2008).

130. Clements, D. A. et al. Over five-year follow-up of Oka/Merck varicella vaccine recipients in 465 infants and adolescents. Pediatr. Infect. Dis. J. 14(10), 874-879 (1995).

131. Coghill, A. E. et al. High levels of antibody that neutralize B-cell infection of Epstein-Barr virus and that bind EBV gp350 are associated with a lower risk of nasopharyngeal carcinoma. Clin. Cancer Res. 22, 3451-3457 (2016).

132. Simmons, A. \& Tscharke, D. C. Anti-CD8 impairs clearance of herpes simplex virus from the nervous system: implications for the fate of virally infected neurons. J. Exp. Med. 175, 1337-1344 (1992).

133. Liu, T., Khanna, K. M., Chen, X., Fink, D. J. \& Hendricks, R. L. CD8(+) T cells can block herpes simplex virus type 1 (HSV-1) reactivation from latency in sensory neurons. J. Exp. Med. 191, 1459-1466 (2000).

134. Schiffer, J. T. et al. Rapid localized spread and immunologic containment define Herpes simplex virus-2 reactivation in the human genital tract.elife 2, e00288 (2013).

135. Sei, J. J. et al. Effector and central memory Poly-functional CD4(+) and CD8(+) T cells are boosted upon ZOSTAVAX((R)) vaccination. Front. Immunol 6, 553 (2015).

136. Laing, K. J. et al. Zoster vaccination increases the breadth of CD4 + T cells responsive to varicella zoster virus. J. Infect. Dis. 212, 1022-1031 (2015)

137. Weinberg, A. et al. Varicella-zoster virus-specific immune responses to herpes zoster in elderly participants in a trial of a clinically effective zoster vaccine. J. Infect. Dis. 200, 1068-1077 (2009).

138. Tzannou, I. et al. Off-the-shelf virus-specific $T$ cells to treat BK virus, human herpesvirus 6, cytomegalovirus, Epstein-Barr virus, and adenovirus infections after allogeneic hematopoietic stem-cell transplantation. J. Clin. Oncol. 35, 3547-3557 (2017).

139. Roskrow, M. A. et al. Epstein-Barr virus (EBV)-specific cytotoxic T lymphocytes for the treatment of patients with EBV-positive relapsed Hodgkinas disease. Blood 91, 2925-2934 (1998).

140. Bollard, C. M. et al. Sustained complete responses in patients with lymphoma receiving autologous cytotoxic T lymphocytes targeting Epstein-Barr virus latent membrane proteins. J. Clin. Oncol. 32, 798-808 (2014).

141. Taylor, G. S. et al. Dual stimulation of Epstein-Barr Virus (EBV)-specific CD4 + and CD8 + -T-cell responses by a chimeric antigen construct: potential therapeutic vaccine for EBV-positive nasopharyngeal carcinoma. J. Virol. 78, 768-778 (2004).

142. Plotkin, S. A. Vaccines for varicella-zoster virus and cytomegalovirus: recent progress. Science 265, 1383-1385 (1994).

143. Farrell, H. E. et al. Vaccine potential of a herpes simplex virus type 1 mutant with an essential glycoprotein deleted. J. Virol. 68, 927-932 (1994).

144. Awasthi, S. et al. Live attenuated herpes simplex virus 2 glycoprotein E deletion mutant as a vaccine candidate defective in neuronal spread. J. Virol. 86, 4586-4598 (2012).

145. Awasthi, S., Huang, J., Shaw, C. \& Friedman, H. M. Blocking herpes simplex virus 2 glycoprotein E immune evasion as an approach to enhance efficacy of a trivalent subunit antigen vaccine for genital herpes. J. Virol. 88, 8421-8432 (2014).

146. Awasthi, S. et al. A dual-modality herpes simplex virus 2 vaccine for preventing genital herpes by using glycoprotein $C$ and $D$ subunit antigens to induce potent antibody responses and adenovirus vectors containing capsid and tegument proteins as T cell immunogens. J. Virol. 89, 8497-8509 (2015).

147. Zhu, R. et al. A highly conserved epitope-vaccine candidate against varicellazoster virus induces neutralizing antibodies in mice. Vaccine 34, 1589-1596 (2016) 
148. Weiss, E. R. et al. High epstein-barr virus load and genomic diversity are associated with generation of gp350-specific neutralizing antibodies following acute infectious mononucleosis. J. Virol. 91, e01562-16 (2017).

149. Kanekiyo, M. et al. Rational design of an Epstein-Barr virus vaccine targeting the receptor-binding site. Cell 162, 1090-1100 (2015).

150. Mao, H. \& Rosenthal, K. S. Strain-dependent structural variants of herpes simplex virus type 1 ICP34.5 determine viral plaque size, efficiency of glycoprotein processing, and viral release and neuroinvasive disease potential. J. Virol. 77, 3409-3417 (2003).

151. Neves, M., Marinho-Dias, J., Ribeiro, J. \& Sousa, H. Epstein-Barr virus strains and variations: geographic or disease-specific variants?. J. Med. Virol. 89, 373-387 (2017).
Open Access This article is licensed under a Creative Commons Attribution 4.0 International License, which permits use, sharing, adaptation, distribution and reproduction in any medium or format, as long as you give appropriate credit to the original author(s) and the source, provide a link to the Creative Commons license, and indicate if changes were made. The images or other third party material in this article are included in the article's Creative Commons license, unless indicated otherwise in a credit line to the material. If material is not included in the article's Creative Commons license and your intended use is not permitted by statutory regulation or exceeds the permitted use, you will need to obtain permission directly from the copyright holder. To view a copy of this license, visit http://creativecommons. org/licenses/by/4.0/.

(c) The Author(s) 2018 